\title{
Continuous-Time Option Games: Review of Models and Extensions
}

\author{
Marco Antonio Guimarães Dias* \\ PUC-Rio, Brazil \\ José Paulo Teixeira** \\ PUC-Rio, Brazil
}

This paper discusses a selected literature on continuous-time option games models, providing new insights and extensions. The paper analyzes both symmetrical and asymmetrical duopoly under uncertainty, including issues like preemption, non-binding collusion, perfect-Nash equilibriums, first-mover advantage, mixed strategies, probability of mistake with simultaneous exercise, competitive advantage effect, etc. In the first model, the demand follows a stochastic process, whereas in the second model the exchange rate follows a stochastic process. This paper presents two equivalent ways to calculate the leader and follower values and thresholds, the differential and the integral methods. The paper extends the Joaquin and Buttler's model by considering mixed strategies in asymmetric duopoly and other extensions. (JEL: G31, G12, $\mathrm{C} 72, \mathrm{C} 73)$

Keywords: option games, real options, game theory, duopoly under uncertainty, preemption.

\section{Introduction}

The theory of corporate finance in general and especially capital budgeting, has been experimenting a fast and rich development in the last 30 years. Most of these new theoretical tools and practical insights

\footnotetext{
* Corresponding author. Adjunct Professor of Finance (part-time), Dept. of Industrial Engineering at PUC-Rio and (internal) Senior Consultant by Petrobras, Doctor. E-mail: marcoagd@pobox.com. Address: Petrobras-E\&P/ENGP/DP/EPP. Av. Chile 65, sala 1701 - Rio de Janeiro, RJ, Brazil, 20035-900. Phone: +55(21)32242164. Fax: +55(21)32246594. ** Professor of Finance, Dept. of Industrial Engineering at PUC-Rio, Ph.D. E-mail: jpt@ind.puc-rio.br. Address: PUC-Rio, Dep. Engenharia Industrial, Rua Marques de S $\gamma_{0}$ Vicente, 225 - Rio de Janeiro, RJ, Brazil, 22453-900.
}

(Multinational Finance Journal, 2010, vol. 14, no. 3/4, pp. 219-254)

(C) Multinational Finance Society, a nonprofit corporation. All rights reserved. DOI: $10.17578 / 14-3 / 4-3$ 
come from the development of two theories. First, the option pricing theory and contingent claims approach developed by the seminal papers of Black and Scholes (1973) and Merton (1973). Second, by applications of game theoretic concepts to corporate finance problems starting in 70's mainly asymmetric information between agent and principal with signalling games in papers like Ross (1977), Leland and Pyle (1977), Bhattacharya (1979), and Myers and Majluf (1984).

Myers (1977) coined the term "real options" for investment opportunities in projects (real assets), starting a capital budgeting revolution. Real options models started with Tourinho (1979), Kester (1984), Brennan and Schwartz (1985), McDonald and Siegel (1986), Trigeorgis and Mason (1987), and Paddock, Siegel, and Smith (1988), just to mention a few of the best-known cases.

The real options theory allowed a proactive approach to investment decisions in conditions of uncertainty, highlighting the value of the managerial flexibility under uncertainty. Before real options, uncertainty was only a matter of appropriate discounting through an adequate risk-premium, a limited view on the manager's role facing uncertainty in projects and real assets in general. With real options the foundations for a modern theory of investment under uncertainty were established. However, the problem of investment under uncertainty and under competition was demanding a more rigorous framework. The earlier real options attempts to model competition considered as exogenous either an estimated entry or a random entry of competitors, ${ }^{1}$ instead an endogenous rational entry of competitors. ${ }^{2}$ Game theoretic concepts for models with strategic interaction between firms were not addressed in real options models until the beginning of 1990s.

The practical and theoretical demand of real options models considering also a rational strategic interaction between the "players" - the option exercise of one player changing the real option values of the others players, led to the birth of continuous-time option games ${ }^{3}$

1. Before option games models, the best known attempts that appeared to model the competition effect were: Kester (1984) considering a finite time to expiration of a real option, with this time being function of an estimated competitors entry destroying the firm's real option; Trigeorgis $(1986,1991)$, the competitor preemption effect is modeled as "additional dividends" that are lost by the (non-exercised) real option owner; and also in Trigeorgis (1986, 1991), the competitor entry is modeled with a Poisson process, with the competitor's random arrival causing a jump-down in the project value.

2. Rational entry of competitors includes cases with mixed strategies and Bayesian strategies (incomplete information), because the probabilities in this context are calculated from players' strategies with mutual interaction rationality.

3. The term "option games" first appeared in Lambrecht and Perraudin (1994). 
literature in the beginning of 90's with the Smets' dissertation (1993, after a working paper in 1991). ${ }^{4}$ Discrete-time option games started with Smit and Ankum (1993), providing an intuitive approach for important option games models, with additional insights in Smit and Trigeorgis (1993). ${ }^{5}$

Game theory is a well-established tool in industrial organization and modeling of imperfect competition. However, standard game theory alone ignores the advances of finance theory on risk-return and on managerial flexibility value under uncertainty. Game theory and options pricing are complementary approaches, providing together a framework with rich potential of applications. Both theories won the Nobel Prize in Economics in the 1990s, game theory in 1994 with Nash, Selten, Harsanyi, and options pricing theory in 1997 with Scholes and Merton (with references to project applications - real options, by the Swedish Academy communication).

About the combination of option pricing and game theory, Ziegler (1999, p.133) wrote: “... game theory analysis of options in effect replaces the maximization of expected utility encountered in classical game theory models with the maximization of the value of an option ... option-pricing approach has the advantage that it automatically takes the time value of money and the price of risk into account". He also highlights the "link between markets and organizations" with options setting payoffs using market criteria and game theory taking the structure of organizations into account.

The first (real) option games textbook appeared with Huisman (2001), focusing important theoretical models of option games in continuous-time mainly for technology applications. In the same line, Thijssen (2004) is a recent monograph with models that consider the reduction of uncertainty along the time. Before, Grenadier (2000) edited a good selection of option games papers. A nice new addition is the recent textbook of Smit and Trigeorgis (2004) focusing mainly discrete-time option games models, in a light and thorough approach, with many practical examples.

4. This model was summarized in the first real options textbook, the outstanding work of Dixit and Pindyck (1994, chapter 9). These authors took the attractive risk to include in their book the just born option games model of Smets (1993) that was starting a new literature. The price was two minor misunderstandings pointed out by Huisman and Kort (1999).

5. The latter is well summarized in the very good real options textbook of Trigeorgis (1996, chapter 9). 
It is not by chance that most contributions in option-games come from real options researchers rather than game-theoreticians. Although knowledge on game theory is always necessary for the financial engineer to develop option-game models, tools like stochastic processes and optimal control are more useful than fixed-point theorem, a typical game-theoretic tool. However, another promising way to solve option-game models comes from two game-theoreticians, Dutta and Rustichini (1995), who proved that the best response map satisfies a strong monotonicity condition, which is used to set the existence of Markov-Perfect Nash equilibriums. Another related school that can contribute to option games literature comes from researchers in optimal control, e.g., Basar and Olsder (1995) and Dockner et al. (2000), mainly the stochastic differential games branch. However, the bridge between option games and that branch in optimal control literature remains to be constructed.

Although many new papers have been written in the last years, the combination of real options with game theory has a large potential of new models considering the vast individual literature on game theory and real options. The main goal of this paper is to show two equivalent methods to solve continuous-time option games, presenting typical tools and the key concepts used in these models.

The next section presents a discussion on threshold strategies in the option game literature and presents the main proposition, the two methods to solve option game models. Section III illustrates the proposition with the symmetrical duopoly model, showing the two equivalent ways to calculate both values and thresholds, and with discussion on mixed strategy equilibrium and the possibility of non-binding collusion equilibrium. Section IV discusses the asymmetrical duopoly model, extending the model of Joaquin and Buttler (2000) with a mixed strategy proposition for asymmetric duopoly under uncertainty. Section V presents some conclusions and suggestions.

\section{Thresholds Strategies and the Two Solution Methods}

Timing games or optimal stopping games are games where the players' pure strategies are stopping times choices. So, at each moment the set of actions for each firm $i$ is $A_{i}(t)=$ \{stop; don't stop\}, see e.g., Fudenberg and Tirole (1991, p.117). Here "stopping time" means the time to stop the "wait and see" policy by exercising the real option. These types of games can be classified into two categories: games of 
negative externalities (e.g., preemption games) and games of positive externalities (e.g., war of attrition). Here the focus is the case of two-firm (duopoly) preemption games in continuous time.

The game modeling aim is to find out the equilibrium strategies. These strategies are the players' best response considering the rivals' best response. For finite games, we can optimize backwards (backward induction) from the option expiration $(t=T)$ until the initial moment $(t$ $=0$ ). In this way, these strategies are SPNE (subgame perfect Nash equilibrium) because induces a Nash equilibrium (NE) in every subgame (starting at any time $t$ ). This is just the dynamic programming approach, which is largely used in real options. Dynamic programming can be used for perpetual options (e.g., see Dixit and Pindyck, 1994, chapter 4), so that it is also applied to infinite option games. This case is generally easier because time is not state variable as in finite games.

As usual in stochastic games, we limit our focus on the Markov equilibria, i.e., equilibria that are function of the current state of the stochastic variable only, ${ }^{6}$ which follows a Markov process. Markov equilibriums are also subgame perfect. We want identify at least one Markov perfect equilibrium (MPE). In the text, when referring to SPNE, we are implicitly considering MPE only. The best-known continuous time option game models are solved with optimal strategies named simple threshold strategies (or simple trigger strategies), which are the basic elements of the option game solution (equilibrium). In this case, MPE strategies are stopping times related to the infimum time in which the stochastic variable hits the threshold level.

Compared with traditional real options models, the main difference is that option game models also consider (endogenously) the rival's optimal option exercises, i.e., equilibrium strategies are simultaneous best responses. In most cases, the optimal real option exercise is given by a simple threshold strategy, that is, the state variable (e.g., a price $P$ ) follows a stochastic process and when $P$ hits a threshold level $P^{*}$, one player (or many players) exercises one real option. This optimal exercise can be also characterized by optimal stopping time $\left(t^{*}\right)$, i.e., the infimum time that the state variable $(P)$ hits the threshold level $\left(P^{*}\right)$. This simple option exercise strategy is very common in both real options and option games models. For instance, the classical Smets (1993) model is based in simple threshold strategies for the leader and the follower.

6. The current state variable summarizes the direct effect of the past on the current game, see Fudenberg and Tirole (1991, chapter 13). 
However, there are some cases (in both real options and option games models) in which the optimal option exercise is not so simple. Instead a simple threshold, we can have disconnected option exercise sets (or disconnected stopping sets), which can produce apparent paradoxical results. A (non-strategic) real options example is presented by Dias, Rocha, and Teixeira (2004), with three mutually exclusive alternatives of investment scale for a project. There are intermediate waiting regions for the state variable price $(P)$, so that is possible to exercise the investment option (using a specific scale alternative) if the price drops - an apparent paradoxical result. ${ }^{7}$ In the option game context, Décamps and Mariotti (2004) presents an example where is necessary to consider the disconnected option exercise sets issue. In their model, does not exist a 1-1 correspondence between what the players know about the project value (underlying asset V) and the option exercise price (the investment I) generating these disconnected sets. In some cases, even when considering disconnected sets is more rigorous, researchers assume only simple thresholds strategies. One example is Lambrecht (2001, p.771): with the assumption that firms use only simple thresholds strategies, he discards both mixed strategies and non-intuitive Nash equilibria such as the market abandonment of one firm when the price rises. Although some SPNE disappear in this way, the most natural SPNE is considered.

Here the paper focuses only on the most common case, i.e., the simple threshold strategies option games. For this large class of real option games, the following proposition is valid.

Proposition 1: Consider the class of real options games in continuous time in which the players use simple threshold strategies. There are at least two equivalent solution methods to solve these games. The first one is the differential method and the second one is the integral method. These two methods are summarized below:

Differential Method: uses traditional methods of real options, i.e., stochastic differential equations (ordinary or partial) describe the player values. The player strategies optimization is performed considering endogenously the rival's best responses, through the boundary conditions of smooth pasting and value-matching (see Dixit and Pindyck, 1994).

7. The intuition is as follows. At time $t$ the firm is waiting for a larger scale alternative. But if the price drops at $t+\Delta t$ to a sufficient lower level, decreases the probability for the prices to reach the higher threshold set from the larger scale alternative, so that is optimal to stop the waiting policy and exercise a lower scale alternative. 
Integral Method: uses the expected value of a sum of stochastic integrals to describe the player values. The integration limits are optimal stopping times combined with trivial limits $(0$ and $\infty)$. These stopping times are defined as the infimum times that the stochastic variable hits the threshold values. The players' simultaneous optimal response is performed with traditional optimization methods, like the first order condition, and with the expected value of the stochastic discount factor.

This proposition is showed with the classical duopoly example in the next section, where is presented both methods, showing that these methods are equivalent in the sense that lead to the same players' values and the same thresholds. For this class of games, the players' values and the strategic thresholds are sufficient to set the equilibrium(s) in pure strategies or in mixed strategies. With the differential method the threshold strategies are placed at the boundary conditions, whereas with the integral method the thresholds strategies are represented by stopping times placed at the integration limits. With simple thresholds, it is always possible to represent the player value as the sum of integrals, dividing the time $[0, \infty)$ into intervals like $\left[0, t_{1}{ }^{*}\right)$ plus $\left[t_{1}{ }^{*}, t_{2}{ }^{*}\right)$ plus $\left[t_{2}{ }^{*}\right.$, $\infty)$, etc. Generally analytical solutions are obtained for infinite (perpetual) option games, whereas for finite real option games, time becomes state variable and generally are necessary numerical methods.

In many cases these two methods were combined, e.g., in Dixit and Pindyck (1994, chapter 9) the differential method was used to obtain both the follower's value and the follower's threshold, whereas the integral method was used to get both the leader's value and the leader's threshold. ${ }^{8}$ Here is showed that the differential method can be used also for the leader (value and threshold) and the integral method can be used also for the follower (value and threshold). In order to calculate the leader value and the leader threshold with the differential method just use the differential equation for leader value during its monopoly phase, ${ }^{9}$ considering as boundary condition the time that the follower exercises its option (making concave the leader value function). The analysts of this symmetrical duopoly model did not previously note this.

In addition, the integral method can also be used alone to solve this game: the follower value can be obtained with a single stochastic

8. Dixit and Pindyck didn't calculate explicitly the leader threshold, but was obvious (p.312) that a simple numerical algorithm finds this threshold.

9. But not the value of the option to invest (to become leader), which is not required in the game solution. 
integral with limits $t^{*}$ and $\infty$, where $t^{*}$ is when the follower exercises its option. ${ }^{10}$ This integral is solved with the help of the expected value of the stochastic discount factor, giving the follower value as function of its threshold. This threshold can be obtained with traditional optimization tools (first order condition) and again with the expected value of the stochastic discount factor. In more general cases, we can have a sum of two integrals (like the leader value in Dixit and Pindyck) or more. It depends on the relevant optimal stopping times, which divide the game phases (and so the integration limits) according the option exercises, e.g., one phase without exercise, a phase with one firm with monopoly, and one phase with both firms producing (duopoly).

There are situations in which one method is simpler than the other and vice-versa. The following two sections on duopoly models illustrate these methods.

\section{Symmetrical Duopoly under Uncertainty}

The symmetrical duopoly under uncertainty model was the first known option games model (Smets, 1993). In addition to the historical relevance, this model has a great theoretical importance - foundations of stochastic timing-games of preemption in continuous-time, and also practical significance for duopoly when there is no competitive advantage for one firm. This section summarizes the in-depth analysis performed by Huisman and Kort (1999). They extended the previous literature (Smets/Dixit and Pindyck) in many ways, especially by allowing mixed-strategies equilibrium and analyzing the possibility of non-binding collusion equilibriums. In addition, they presented many propositions that establish the conditions for the occurrence of different equilibriums, in a rigorous approach. For sake of space is presented only selected results. ${ }^{11}$ The explanation here addresses only some minor modifications on the original notation. However, this present paper includes some issues not discussed in that paper, e.g., the two ways to calculate the value of the follower and the leader and some additional explanations not mentioned in that paper.

10. In the traditional real options context, the integral method is well discussed in Dixit, Pindyck, and Sødal (1999).

11. For additional results, discussions, and charts, see: http://www.puc-rio.br/marco.ind/duopoly2.html 
This duopoly model is symmetrical in the sense that the players are homogeneous firms (equal firms), so that this suggests symmetrical strategies. ${ }^{12}$

The first difference of Huisman and Kort model - when compared with Smets or Dixit and Pindyck, is that the two firms are already active in the market producing one unit each, and they are considering the exercise of (a definitive) one perpetual option to expand the production. This means that the "entry" (read expansion) of a firm affects the current profit flow of the other firm - reducing the profit flow because this model considers negative externalities. The investment to expand the production (exercise price of the real option) is the same for both firms and denoted by $I$.

The firms face a (inverse) demand curve expressed by the profit flow $P(t)$ for firm $i$ given by:

$$
P(t)=Y(t) \cdot D\left(N_{i}, N_{j}\right)
$$

Where $Y(t)$ is the stochastic demand shock following a geometric Brownian motion (GBM):

$$
d Y / Y=\alpha d t+\sigma d z
$$

Where $\alpha$ is the (real) drift, ${ }^{13} \sigma$ is the volatility, and $d z$ is the Wiener increment. ${ }^{14}$ Assume that the process starts with $Y(t=0)=1$. Of course others stochastic processes are possible.

$D\left(N_{i}, N_{j}\right)$ is a deterministic demand parameter for firm $i$, which depends on the status of firms $i$ and $j$. The possible values of $D\left(N_{i}, N_{j}\right)$ are:

12. We avoid formalism in the strategies description, preferring a complete but more intuitive approach. In the paper will be clear either option exercise or waiting strategy for each state of nature (that changes along time) and conditional to the other firm strategy. However, a more formal strategy description for continuous games of timing starting at time t requires two functions for every player $i,\left(G_{i}, \alpha_{i}\right):[t, 1] \times[t, 1] \rightarrow[0,1] \times[0,1]$, where $G_{i}(\tau)$ is a cumulative probability of exercise and $\alpha_{i}(\tau)$ is the atom of probability (see discussion on mixed strategy). Time is normalized so that an infinite horizon game with time $s \in[0, \infty]$ is normalized to $\tau \in[0,1]$ with the transforming function $\tau=s /(s+1)$.

13. For the risk-neutral GBM, just replaces $\alpha$ by the risk-neutral drift $=r-\delta$, where $r$ is the risk-free discount rate and $\delta$ is the dividend yield. The risk-neutral drift is also equal to $\alpha-\pi$, where $\pi$ is the risk-premium.

14. Given by $d z=d t^{0.5} . N(0,1)$, where $N(0,1)$ is drawn from the standard Normal distribution. 
$D(0,0)$ means that both firms have not invested yet (but there is a profit flow $Y D(0,0)$ because the firms are already active in the market);

$D(1,0)$ means that firm $i$ invested and is the "leader" because the firm $j$ has not invested yet;

$D(0,1)$ means that firm $i$ is the "follower" because only the other firm $(j)$ has invested becoming the leader; and

$D(1,1)$ means that both firms invested in the market (simultaneous investment).

These factors $D\left(N_{i}, N_{j}\right)$ are adjusted to the production level. The operational cost is zero or it is also included in $D$, so that $P$ is interpreted as profit flow instead price. For example, the profit flow of the leader is $Y . D(1,0)$, and this profit flow is higher than $Y . D(0,0)$. That is, the higher production level when investing and assuming the leader role, is already included in the value $D(1,0)$. The change of status from $D(0,0)$ to $D(1,0)$ demands the sunk investment $I$. In addition, due to the problem symmetry, when one firm is profiting $Y D(1,0)$, the other firm is profiting $Y D(0,1)$, etc. For the called "new market model" - the original case of Smets and in Dixit and Pindyck where firms are not active in the market in $t=0$, the case simplifies: $D(0,0)=D(0,1)=0$.

Huisman and Kort assume that firms are risk-neutral so that the discounting is performed with risk-free interest rate. However, it is easy to extend the model to risk-averse firms in contingent claims approach by supposing that the stochastic process drift a is a risk-neutral drift.

The deterministic demand parameters have the additional constraint of negative externality (the option exercise of one firm reduces the value of the other firm) given by the inequality:

$$
D(1,0)>D(1,1)>D(0,0)>D(0,1)
$$

Other model assumption is the first mover advantage, given by the inequality:

$$
D(1,0)-D(0,0)>D(1,1)-D(0,1)
$$

This inequality says that the gain when becoming leader is higher than the gain when becoming follower (for the same $Y$, and considering the same investment $I$ ). 
Before any options exercise (when $Y$ is below the leader threshold $Y_{L}$ ), the value of each firm is the current cash-flow profit in perpetuity, $Y D(0,0) /(r-\alpha)$, with $r>\alpha$, plus the investment option (exercising as leader or as follower, with $50 \%$ each - as we will see later) net of the competitive losses due to the negative externality from the expected rival entry.

As standard in timing games, the solution is performed backwards. This means that first we need to estimate the value of the follower (given that the leader entered before), and then the leader value given that the leader knows that the optimal follower entry can happen in the future. Here is considered that any firm can become the leader (the roles are not exogenously assigned). Let us see two ways to estimate the follower value. First, is used the differential method. By using the traditional contingent claims steps (Itô's Lemma, etc.) the value of the follower $F$ is given by the ordinary differential equation (ODE) below.

$$
0.5 \sigma^{2} Y^{2} F_{Y Y}+\alpha Y F_{Y}-r F+Y D(0,1)=0
$$

Where the first three terms corresponds to the homogeneous part of the ODE, and the last term in the right side is the non-homogeneous term also called the "cash-flow" because it is the follower profit flow before the option exercise. Note that this cash-flow term doesn't exist in the new market model of Dixit and Pindyck, whereas in Huisman and Kort the follower earns cash flow even before the option (to expand) is exercised. The ODE solution is a homogeneous solution of type $A Y^{\beta 1}$ $+B Y^{\beta 2}$, plus a particular solution, where $\beta_{1,2}$ are the roots from the equation $0.5 \sigma^{2} \beta^{2}+\left(\alpha-0.5 \sigma^{2}\right) \beta-r=0$. Economic condition makes the constant $B$ in the negative root $\left(\beta_{2}\right)$ term equal zero. ${ }^{15}$

So the solution for the follower's ODE is given by:

$$
\begin{gathered}
F(Y)=A Y^{\beta 1}+Y D(0,1) /(r-\alpha) \text { if } Y \leq Y_{F} \\
F(Y)=Y D(1,1) /(r-\alpha)-I \text { if } Y \geq Y_{F}
\end{gathered}
$$

Where $Y_{F}$ is the follower's optimal investment threshold. We need to find out two unknowns, the constant $A$ and the threshold $Y_{F}$. For this, is sufficient to apply the boundary conditions value matching and the smooth pasting:

15. Because economic logic tells that when demand $Y$ tends to zero, the follower value needs to go to zero as well. 


$$
\begin{gathered}
F\left(Y=Y_{F}\right)=Y_{F} D(1,1) /(r-\alpha)-I \\
F_{Y}\left(Y=Y_{F}\right)=D(1,1) /(r-\alpha)
\end{gathered}
$$

With subscript $Y$ in $7 \mathrm{~b}$ denoting the first derivative in relation to $Y$. Deriving the equation 6a at $Y=Y_{F}$ and equalizing to equation $7 \mathrm{~b}$, and equalizing eq.6a at $Y=Y_{F}$ to equation 7a, we get two equations with two unknowns $\left(A\right.$ and $\left.Y_{F}\right)$. With some algebra is obtained the following values:

$$
\begin{gathered}
A=\frac{Y_{F}^{1-\beta_{1}}}{\beta_{1}} \frac{D(1,1)-D(0,1)}{(r-\alpha)} \\
Y_{F}=\frac{\beta_{1}}{\beta_{1}-1} \frac{(r-\alpha) I}{D(1,1)-D(0,1)}
\end{gathered}
$$

Substituting the constant $A$ into equation 6a we finally find the follower value.

The second way to find both the follower value and the threshold is the integral method, which is based in the concept of first hitting time and expected discount factor. Let $T^{*}$ be the first time that the stochastic variable hits a (superior) level $Y^{*}$ (here $Y^{*}=Y_{F}$ ). The follower value here has two components. First the profit flow before exercising the option (remember that here both firms are active in the market even before the option exercise), from $t=0$ until $t=T^{*}$ (or $T_{F}$ ). Second, the profit flow after the option exercise at $Y_{F}$, net of investment $I$, from $t=$ $T^{*}=T_{F}$ until infinite. See the integrals below: ${ }^{16}$

$$
\begin{array}{cc}
F(Y)=E\left[\int_{0}^{T *} e^{-r t} Y(t) D(0,1) d t\right]+E\left[\int_{T^{*}}^{+\infty} e^{-r t} Y(t) D(1,1) d t\right]-E\left[e^{-r T^{*}}\right] I \\
\text { Expected Profit } & \text { Expected Profit } \\
\text { Before Exercise } & \text { After Option Exercise }
\end{array}
$$

16. Note that the follower value assumes that the other firm entered as leader at $t=0$. If instead we want the value of the firm planning to be follower, assuming that the other firm will enter as leader at $T_{L}>0$, three integrals are necessary: one from 0 to $T_{L}$, with $D(0,0)$; other from $T_{F}$ to $T_{L}$, with $D(0,1)$, and the last from $T_{F}$ to infinite, with $D(1,1)$. 
Note that for the new market model $D(0,1)=0$ and the first integral is zero (Dixit and Pindyck case). At $t=T^{*}$ the firm gets a profit flow in perpetuity, with present value at $T^{*}$ of $Y_{F} D(1,1) /(r-\alpha)$. By carrying that in present value, from $T^{*}$ to current instant $(t=0)$, we obtain:

$$
F(Y)=D(0,1) E\left[\int_{0}^{T *} e^{-r t} Y(t) d t\right]+E\left[e^{-r T^{*}}\right]\left[\frac{Y_{F} D(1,1)}{r-\alpha}-I\right]
$$

The stochastic discount factor depends only on the stochastic process parameters and the discount rate $r$, and is given by the very simple equation below:

$$
E\left[e^{-r T^{*}}\right]=\left(\frac{Y}{Y_{F}}\right)^{\beta_{1}}
$$

For the proof, see Dixit and Pindyck (chapter 9, appendix). The value of the first expectation in the $F(Y)$ equation is given by:

$$
E\left[\int_{0}^{T^{*}} e^{-r t} Y(t) d t\right]=\frac{Y}{r-\alpha}\left[1-\left(\frac{Y}{Y_{F}}\right)^{\beta_{1}-1}\right]
$$

For the proof of this expectation, see Dixit and Pindyck (chapter 9, appendix). Substituting these expectations results (eqs. 9 and 10) into the last equation of the follower value $F(Y)$, the reader can verify that we find out the same result for the follower value encountered with the first method (eqs. 7 and 8a). For the more common case of new market model, this second method is easier because the equation of expected discount factor is easy to remember and the first integral is zero.

However, how to calculate the threshold value with the second method? Let us present a simple method using the standard optimization approach for the investment decision (for details of this method, see Dixit Pindyck and Sødal, 1999).

Let the net present value from the option exercise be $N P V_{F}=V(Y)$ $-I$. The maximization of the project is a trade-off between waiting for a higher value of the project $V(Y)$ and the discount factor (higher as earlier we exercise the option). If the investor waits for a too high value of $V(Y)$, they can wait too much and the discount factor can be too small. In this cost-benefit balance of waiting policy, there is one optimal 
value for $Y$ that maximizes the present value of the expected payoff from the option exercise, namely the function $G(Y)$ :

$$
G(Y)=\operatorname{Max}_{Y} E\left[e^{-r t}\right] \cdot[V(Y)-I]
$$

The benefit from exercising the option here is $V(Y)=Y[D(1,1)-D(0$, $1)] /(r-\alpha)$. Denote the expected discounting factor by $R\left(Y_{0}, Y_{F}\right)$, that is (for notational simplicity make $Y_{0}=Y$ ):

$$
R\left(Y, Y_{F}\right)=E\left[\exp \left(-r T^{*}\right)\right]=\left(Y / Y_{F}\right)^{\beta_{1}}
$$

So, the maximization problem becomes:

$$
G(Y)=\operatorname{Max} R\left(Y, Y_{F}\right) \cdot(\{Y[D(1,1)-D(0,1)] /(r-\alpha)\}-I)
$$

The first order condition to maximize the above equation determines that we take the partial derivative of $G$ in relation to the control variable $Y_{F}$, equaling it to zero. This results in:

$$
\begin{gathered}
R\left(Y, Y_{F}\right) \cdot[D(1,1)-D(0,1)] /(r-\alpha)+R_{Y F}\left(Y, Y_{F}\right) \cdot Y_{F}[D(1,1)- \\
D(0,1)] /(r-\alpha)=R_{Y F}\left(Y, Y_{F}\right) \cdot I
\end{gathered}
$$

The value of derivative of the expected discount factor in relation to $Y_{F}$, is simply:

$$
R_{Y F}\left(Y, Y_{F}\right)=-\beta_{1} Y^{\beta_{1}} /\left[Y_{F}{ }^{\left(\beta_{1}+1\right)}\right]
$$

By substituting both eq. (14) and eq. (11) into the first order condition, eq. (13), and after a few algebra steps, it is easy to conclude that the resulting threshold equation is the same of equation $8 b$, obtained with the first method. This second method is simpler for the new market model case.

For the leader value $L(Y)$, we can also apply either of these two methods. For example, the leader value is given by the sum of integrals net of the investment cost $I$ : 


$$
\begin{gathered}
L(Y)=E\left[\int_{0}^{T^{*}} e^{-r t} Y(t) D(1,0) d t\right]+E\left[\int_{T^{*}}^{+\infty} e^{-r t} Y(t) D(1,1) d t\right]-I \\
\text { Expected Profit } \\
\text { in Monopoly Phase } \\
\text { in Duopoly Phase }
\end{gathered}
$$

That is, entering as leader the firm experiments a phase as monopolistic with profit flow $Y D(1,0)$, and when the follower enters (at $t=T^{*}=T_{F}$ ) the profit flow drops to $Y D(1,1)$. We can follow with the similar steps used for the follower case with the second method, in order to calculate the leader value. However, perhaps it is even easier the first method, namely the differential equation approach for the value of the leader during the monopolistic phase, denoted by $V(Y)=L(Y)+I$. This value $V(Y)$ needs to match the value of simultaneous investment (follower value) at the boundary point $Y=Y_{F}$. The differential equation of $V(Y)$ is given by:

$$
0.5 \sigma^{2} Y^{2} V_{Y Y}+\alpha Y V_{Y}-r V+Y D(1,0)=0
$$

The last term (non-homogeneous part) is the "cash flow", represented by the profit flow during this monopolistic phase. Again, the ODE solution is given by a general solution from the homogeneous part plus the particular solution related to the cash flow.

$$
V(Y)=B Y^{\beta_{1}}+\frac{Y D(1,0)}{r-\alpha}
$$

The constant B is the parameter that remains to be calculated, requiring only one boundary condition for that. The biggest difference compared with the constant A (eq.8a) from the follower value, is that the constant $\mathrm{B}$ is negative, reflecting in the (expected) leader value, the losses due to the possible future follower investment exercise. This is mathematically showed below. The relevant boundary condition here is the value-matching at the point that the follower enters (at $Y_{F}$ ). The smooth-pasting condition is not applicable here because this point is not derived from the leader's optimal control; it is derived of one optimization problem but from the other player. This boundary condition is:

$$
V\left(Y_{F}\right)=Y_{F} D(1,1) /(r-\alpha)
$$


The leader value during the monopolist phase is equal to the simultaneous investment value at $Y_{F}$. Equaling the two last equations is obtained the value of the constant B in function of $Y_{F}$.

$$
B=\frac{Y_{F}[D(1,1)-D(1,0)]}{Y_{F}^{\beta_{1}}(r-\alpha)}
$$

Note that the constant value is negative because $D(1,1)<D(1,0)$. This means that the effect of the follower entering is to decrease the leader value, as expected by the economic intuition in this duopoly. The negative value of the constant means that the leader value function is concave.

The leader value in the monopoly phase $V(Y)$ is obtained by substituting this constant (eq.16) into the leader equation (eq.15).

With $V(Y)$, we can find out the value of becoming a leader, $L=V-$ $I$. Hence, the value of becoming leader if $Y<Y_{F}$ is given by:

$$
L(Y)=\frac{Y D(1,0)}{r-\alpha}+\left(\frac{Y}{Y_{F}}\right)^{\beta_{1}} \frac{Y_{F}[D(1,1)-D(1,0)]}{r-\alpha}-I
$$

The reader can verify that this value is the same that could be obtained by using the (second) method based on the value of the integral expectations. If $Y \geq Y_{F}$, the value of becoming leader is equal to the value of becoming follower, which is equal to the value of simultaneous investment $S(Y)$ :

$$
L(Y)=S(Y)=\frac{Y D(1,1)}{r-\alpha}-I
$$

The value of simultaneous investment is also important because it is necessary to answer fundamental questions like: (a) what if I deviate from the follower waiting strategy by investing? (b) I want to become a leader, but what if the rival has the same idea at the same time and both invest simultaneously? In other words, it is necessary to verify if a follower strategy is a Nash-equilibrium and the expected value (or expected losses) if by "mistake" both investors invest at the same time (this will be important for the calculus of mixed strategy equilibriums).

Note that the simultaneous investment can be the optimal policy for both players if the state of demand is so high that $Y \geq Y_{F}$, but a mistake in case of $Y<Y_{F}$. 


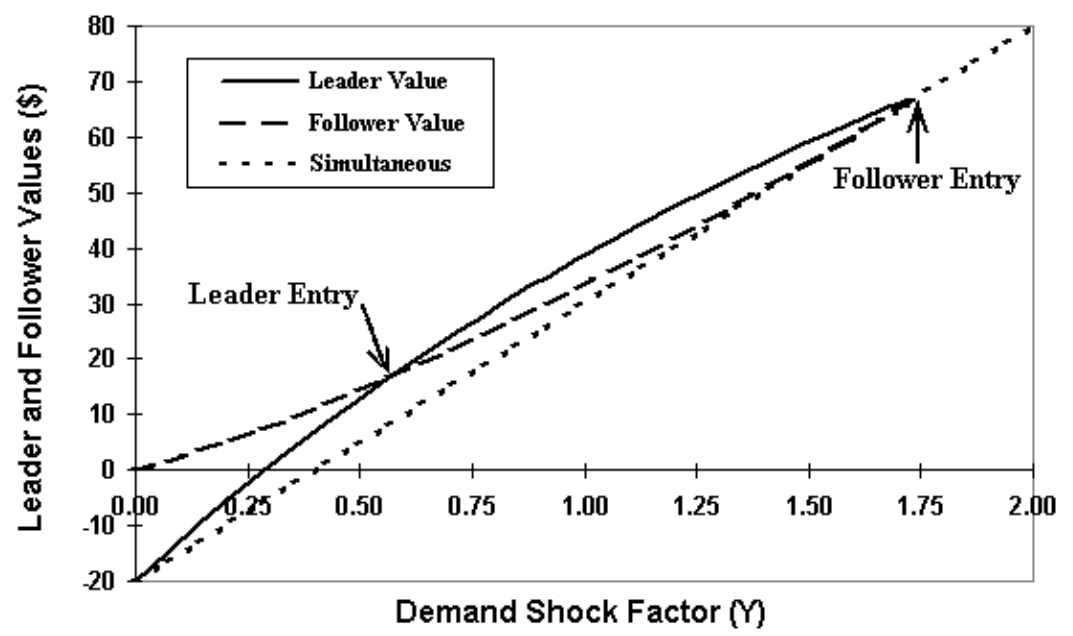

FIGURE 1.- Leader and Follower Values and Entry Thresholds

The remaining issue is the leader threshold. Without the preemption menace, the firm will invest optimally at the monopolistic threshold $Y_{M}$. However, due to the menace of preemption, firms cannot wait so long to invest. If one firm wait until $Y=Y_{M}$, the other firm can invest at $Y_{M}$ $-\varepsilon$, but the first firm could preempt the rival by investing before when $Y=Y_{M}-2 \varepsilon$, etc. This process stops when one firm has no more incentive to preempt the rival.

Firm 1 has incentive to become leader if $L_{1}>F_{1}$ and, most important for firm 1 decision, firm 1 knows that firm 2 has also the incentive to become a leader if $L_{2}>F_{2}$. So, the firm 1 strategy to become a leader is to invest when $L_{2}=F_{2}$. However, due the symmetry of the problem, $L_{1}$ $=L_{2}$ and $F_{1}=F_{2}$ for all $Y$, so that the leader threshold is defined as the $Y$ in the interval $0<Y<Y_{F}$ so that the values of the leader and the follower are equal, i.e.,:

$$
Y_{L}:=\left\{0<Y<Y_{F} \mid L(Y)=F(Y)\right\}
$$

There is a proposition in Huisman and Kort showing that this leader threshold $Y_{L}$ is unique. Due to the symmetry, this threshold is valid for both firms.

Figure 1 shows the leader and follower values and the optimal entry as leader and as follower. The numerical inputs are the same as in Huisman and Kort's paper, that is, our base case has the inputs: $\alpha=5 \%$, 


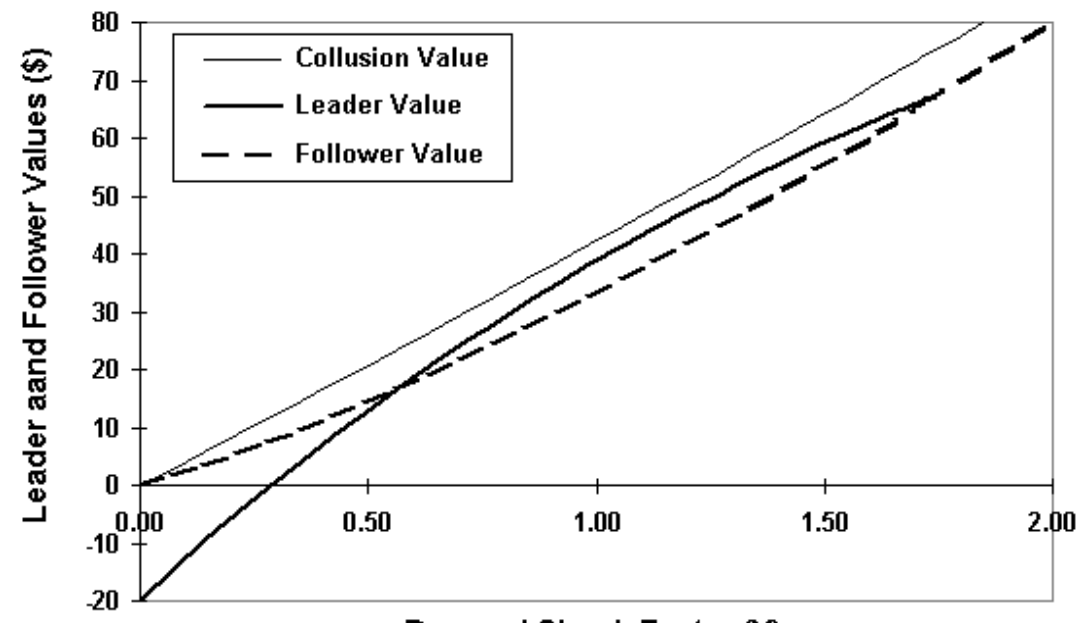

Demand Shock Factor (Y)

FIGURE 2.- Non-Binding Collusion Strategy as Nash-Equilibrium

$\sigma=20 \%, r=10 \%, Y(t=0)=1, I=20$ (for each firm), and the deterministic demand factors are $D(0,1)=1, D(0,0)=2, D(1,1)=2.5$, $D(1,0)=4$.

Another interesting Huisman and Kort's extension is that they consider the possibility of collusion equilibriums without a binding contract between the firms (without communication). They analyze if there are situations that a tacit "wait and see" policy is equilibrium. Firms could calculate if "wait and see" is the best strategy (or not) until a collusion threshold level $Y=Y_{C}$, when both invest simultaneously (or one firm invest and the other one invest immediately after that).

Tacit (or non-binding) collusion will be Nash equilibrium only if there is no unilateral incentive to deviate. Deviation means to earn the leader payoff with the other firm choosing optimally to invest much later as the follower. Denoting the collusion value of each firm by $C(Y$, $\left.Y_{C}\right)$, collusion will be Perfect-Nash equilibrium only if $C\left(Y, Y_{C}\right) \geq L(Y)$ at least for all $Y$ in the interval $\left(0, Y_{F}\right)$. If it occurs, there are infinite collusion Nash-equilibriums possibilities. From these equilibriums the Pareto optimal one is to invest at the collusion threshold $Y_{C}$ given by:

$$
Y_{C}=\frac{\beta_{1}}{\beta_{1}-1} \frac{(r-\alpha) I}{D(1,1)-D(0,0)}
$$

Figure 2 presents the leader value, the follower value, and the collusion 


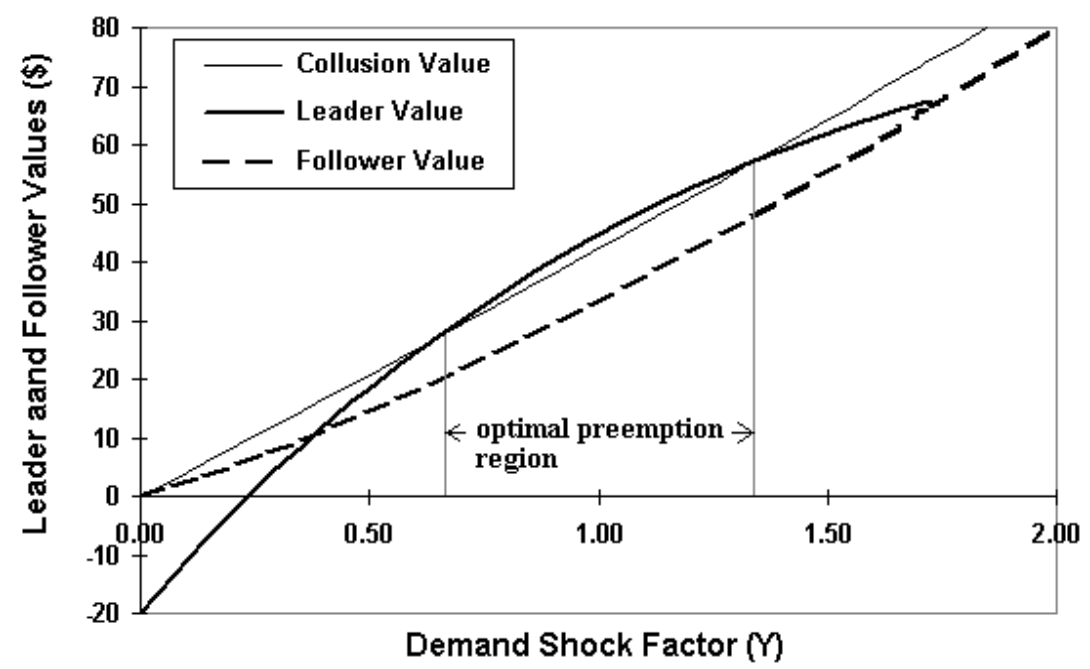

FIGURE 3.- Collusion Strategy Destroyed by Preemption

value as functions of the stochastic demand shock $Y$. The used parameters were the same of the previous chart. Note that the collusion value is always higher than the leader value, so that the collusion equilibrium is feasible (firms in collusion have no incentive to cheating). For the base-case inputs, the collusion value curve smooth pastes the simultaneous value line at $Y_{C}=5.29$, a very high value that is out of the chart.

If the first-mover advantage is sufficiently large, the collusion can be destroyed by the preemption. Figure 3 illustrate this point, when is raised this first mover advantage by setting $D(1,0)=5$.

In the figure 3 there is a region where preemption is optimal due to the higher value for the leader role when comparing with the collusion one. So, in this case the firms in collusion have incentive to cheating and collusion here is not Perfect-Nash equilibrium.

Now, imagine that the initial state of the demand is between $Y_{L}$ and $Y_{F}$. Both firms have incentive to become leader because $L>F$ (see the previous figures to clarify this point). There is no logic to imagine that, without any communication, the other firm will let the rival to become leader so that the probability of simultaneous investment is zero. Both firms will wish the higher leader payoff, but both firms fear the possibility of becoming worse in case of simultaneous investment (a "mistake") because the payoff from simultaneous exercise is lower than 
the follower payoff. Assuming non-communication between the players, the only rational way to treat this problem in the game theory context is by allowing mixed strategies. ${ }^{17}$

With mixed strategies, firms will rationally calculate the optimal probability to exercise the investment option aiming the leader payoff, but considering the positive probability of simultaneous investment. Firms will play a simultaneous game (possibly with infinite rounds) where the firm $i$ can choose invest with probability $p_{i}$ and not invest with probability $1-p_{i}$; players $i=1$ or 2 .

The mixed strategies analysis in continuous-time preemption games must be performed carefully and using special tools. The passage from discrete-time to continuous-time presents problems when using traditional limit considerations. Fudenberg and Tirole (1985) reported that the usual methods present "loss of information" in this passage, with the continuous case not representing the limit of the discrete case. In addition, with traditional tools many strategies converge with probability 1 to be played at the instant $t=0$, a non-consistent result.

In order to determine the symmetrical mixed strategies, Huisman and Kort used the same tool applied in Fudenberg and Tirole (1985): they specify "probabilities" named of "atoms" $p(\tau)$ that, if positive, indicate cumulative probability of exercise $G_{i}(\tau)$ equal to 1 . So, $\tau$ is defined as the first time that some player will exercise the option to invest given that nobody exercised the option before. This kind of resource is taken from optimal control literature (e.g., see Birge and Louveaux, 1997, p.289).

The fundamental idea is that this control doesn't take time. Using this analogy, the control here is the result of a simultaneous game that can be repeated. This is like an instantaneous automatic optimizer. In this way, a simultaneous game with two players even if repeated infinite times, is played instantaneously (no time consuming). This approach determines the probabilities from the mixed strategies and can be proved that this is the true limit of the equivalent game in discrete-time.

The simultaneous game, which can be repeated infinite times, at the instant that one (or both) player will exercise the option (that is, at $\tau$ ), is showed in strategic form in figure 4 , together with the option exercise probabilities.

17. When communication is allowed - as suggested in Joaquin and Buttler (2000) - there is the alternative of a bargain-game (sharing the surplus $L-F$ ) with agreement for only one firm to become leader avoiding the simultaneous investment "mistake". However, in many situations this kind of agreement is illegal or contrary to accepted convention. 
Firm 2

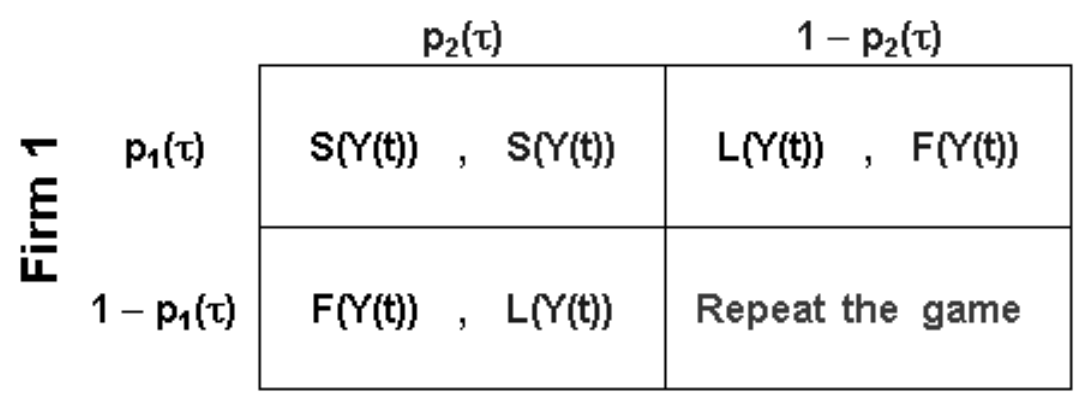

FIGURE 4.- Simultaneous Game at $\tau$

The firm 1 payoff, $V_{1}$ (not yet optimized) is given by:

$$
V_{1}=p_{1} p_{2} S+p_{1}\left(1-p_{2}\right) L+\left(1-p_{1}\right) p_{2} F+\left(1-p_{1}\right)\left(1-p_{2}\right) V_{1}
$$

The last term means that in case of repetition we get the payoff $V_{1}$ due to the definition of $\tau$ : when this game is played (at $\tau$, with infinite rounds) is certain that some player (or both) will exercise the option. Alternatively, an equivalent (perhaps more intuitive) way to obtain $V_{1}$ is given below:

$$
\begin{gathered}
V_{1}=\left[p_{1} p_{2} S+p_{1}\left(1-p_{2}\right) L+\left(1-p_{1}\right) p_{2} F\right] \cdot\left[1+\left(1-p_{1}\right)\left(1-p_{2}\right)\right. \\
\left.+\left(1-p_{1}\right)^{2}\left(1-p_{2}\right)^{2}+\cdots\right]
\end{gathered}
$$

The summing between the first brackets is the expected payoff of a round in case of definition (investment of one or two players). The second summing between brackets multiplies the expected payoff, considering the case of definition in the first round (multiplying by one), in the second round [multiplying by $\left(1-p_{1}\right)\left(1-p_{2}\right)$ ], and etc., until infinite. The summation in the second brackets is just the (convergent) infinite sum of a geometric progression, so that it is easily calculated. Hence, the equation for the (non-optimized) payoff from the simultaneous game for the firm $i, V_{i}, i=1$ or 2 , is:

$$
V_{i}=\frac{p_{i} p_{j} S+p_{i}\left(1-p_{j}\right) L+\left(1-p_{i}\right) p_{j} F}{1-\left[\left(1-p_{i}\right)\left(1-p_{j}\right)\right]}
$$




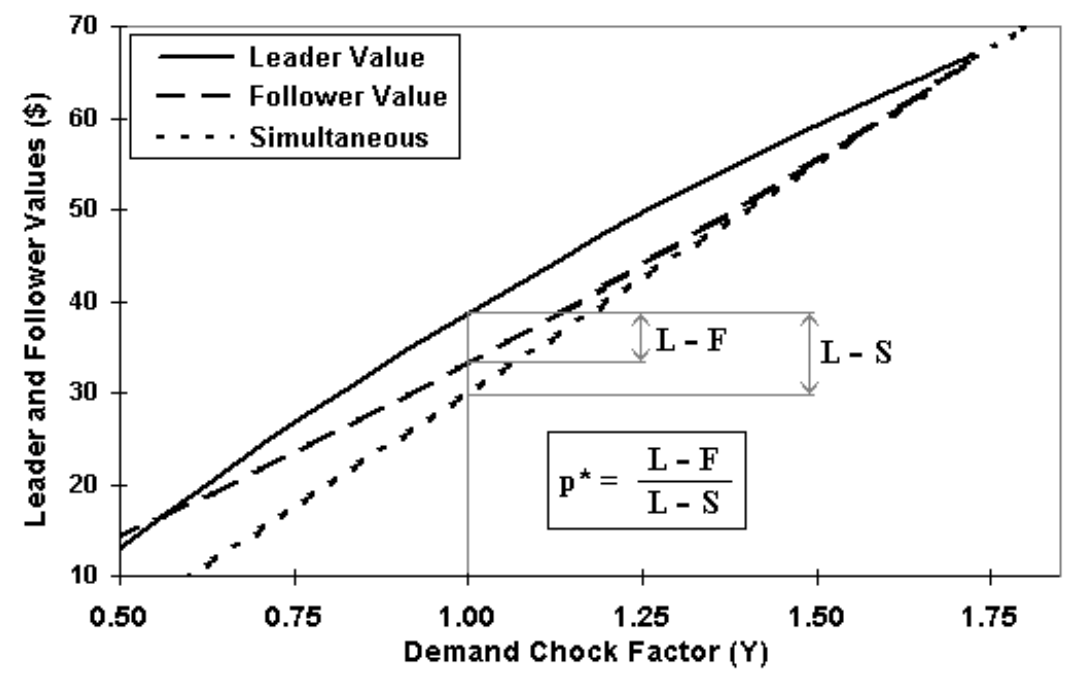

FIGURE 5.- Geometric Interpretation of Mixed Strategy Exercise Probability

Next, players need to set the optimal probability to exercise the option, that is, the probability that maximizes the expected payoff $V_{i}$. The first order condition for this optimization problem for the firm 1 is $\partial V_{1} / \partial p_{1}$ $=0$, given that the rival is planning to exercise the option with probability $p_{2}$. The second order condition indicates a maximization problem. Note also that, due to the symmetry of the problem, the optimal probabilities must be equal. That is, $p_{1}=p_{2}=p^{*}$. This permits a further simplification. Using the first order condition and the symmetry insight, after some algebra we get the following simple equation for the optimal probability of investing in mixed strategies:

$$
p^{*}=\frac{L-F}{L-S}
$$

figure 5 gives a geometric interpretation for the mixed strategy optimal probability of exercise $p^{*}$.

In the figure 5 is easy to see that when $L=F$ and $L>S$, it results in $p^{*}=0$. When $L$ tends to both $F$ and $S$, it results in the limit $p^{*}=1$. In the mixed strategy equilibrium for this symmetrical game, the probability $p^{*}$ can be interpreted as equal the ratio of the possible benefit from preemption $(L-F)$ to the range of total possible variation $(L-S)$. Note that $L-S=[(L-F)+(F-S)]$. 
Let us calculate the probability of only one of the firms to exercise the option and the probability of simultaneous exercise in this game. For that, by looking again the figure 4 with the simultaneous game in strategic-form and, by using a similar reasoning used to the payoff, it is possible to write that the probability $\operatorname{pr}($ one $=i)$ that only the firm $i$ is investing at $\tau$ is given by:

$$
\operatorname{pr}(\text { one }=i)=p(\tau)(1-p(\tau))+(1-p(\tau)) \cdot(1-p(\tau)) \cdot \operatorname{pr}(\text { one }=i)
$$

So, the probability of $\operatorname{pr}($ one $=i)$ is given by:

$$
\operatorname{pr}(\text { one }=i)=\frac{1-p(\tau)}{2-p(\tau)}
$$

Of course, the probability $\operatorname{pr}($ one $=j)$ of only the firm $j$ investing in this simultaneous-game at $\tau$ is exactly the same due to the symmetry. Now, the probability of simultaneous exercise (or probability of "mistake", if $\left.Y<Y_{F}\right)$, denoted by $\operatorname{pr}(t w o)$, using a similar reasoning is given by:

$$
\operatorname{pr}(t w o)=\frac{p(\tau)}{2-p(\tau)}
$$

Note that the three probabilities sum one, that is, $p($ one $=i)+\operatorname{pr}($ one $=$ $j)+\operatorname{pr}(t w o)=1$. This is because there is no possibility of non-exercise in this simultaneous-game due to the definition of $\tau$. We can use the previous optimal value that we found for the probability $p(\tau)$ (eq.23) to estimate the probabilities of each firm investing and the probability of simultaneous exercise. Example, at $Y_{L}$ we known that $L=F$ and $L>S$. So, $p(\tau)=0$. In this case $\operatorname{pr}(t w o)=0$ and $\operatorname{pr}($ one $=i)=\operatorname{pr}($ one $=j)=1 / 2$. Note also that the $\operatorname{pr}(t w o)$ is consistent in the limits when $Y$ tends to $Y_{F}$ or $Y_{L}$, respectively 1 and 0 .

Therefore, when the market begins with $Y<Y_{L}$ there are $50 \%$ chances each to became leader and zero probability of "mistake" when $Y$ reach $Y_{L}$. This conclusion from Dixit and Pindyck with trivial mixed strategies outcome is correct only in this case.

\section{Asymmetrical Duopoly under Uncertainty}

The asymmetrical duopoly under uncertainty model is a more realistic hypothesis in most industries. Here firms are non-homogenous because, 
for the same investment, one firm has lower operational cost than the other. This means that one firm has competitive advantage over the rival.

Here is summarized and extended the known model of Joaquin and Buttler (2000). Following them, the paper assumes a linear inverse demand function, with quantities determined by a Cournot competition. Both firms are based in the same country and both are considering the investment in the same foreign country. The demand function is deterministic and constant over time. However, the exchange rate $X(t)$ is uncertain and evolves as a stochastic process modeled as a GBM. Mathematically it is equivalent to consider a multiplicative stochastic demand shock $Y(t)$. The deterministic linear demand function is:

$$
P=a-b Q_{T}, \text { with } \mathrm{a}>0, \mathrm{~b}>0, \text { and } \mathrm{a}>\mathrm{b} \mathrm{Q}_{\mathrm{T}}
$$

Where $P\left(Q_{T}\right)$ is the price of the product in foreign currency, which is function of the total output in this market $Q_{T}$. For the price in domestic currency, just multiply by the exchange rate $X(t)$.

In case of investment option exercise, there exists a variable operational cost $c_{i}$ for firm $i$ where $i$ can be " $l$ " or " $h$ ", for low-cost and high-cost firms, respectively. The competitive advantage of low-cost firm is expressed by $c_{l}<c_{h}$. The function profit flow $\pi_{i}\left(Q_{i}\right)$ for the firm $i$ in foreign currency is:

$$
\pi_{i}\left(Q_{i}\right)=Q_{i}\left[a-b Q_{T}-c_{i}\right]
$$

Using contingent claims, and with the dividend yield $\delta>0$ being interpreted as a foreign currency yield, the present value of a perpetual profit flow is given by dividing the equation 27 by $\delta$.

The optimal monopolistic profit flow and the equilibrium profit flows from the Cournot duopoly are:

$$
\begin{gathered}
\pi_{M_{i}}=\frac{\left(a-c_{i}\right)^{2}}{4 b} \\
\pi_{i}=\frac{\left(a-2 c_{1}+c_{h}\right)^{2}}{9 b} \mid \pi_{h}=\frac{\left(a-2 c_{h}+c_{l}\right)^{2}}{9 b}
\end{gathered}
$$


We'll put directly the results, ${ }^{18}$ which can be obtained with either of the two methods presented before, being here a "new market model" (which ease the calculus). The follower value for the high-cost firm $F_{h}(X)$, exercising the option as follower at the threshold $X_{F h}^{*}$, is given by the equation below (for the less natural low-cost firm as follower, just switch "l" and " $h$ ").

$$
F_{h}(X)=\mid \begin{array}{ll}
\left.\frac{\left(a-2 c_{h}+c_{l}\right)^{2}}{9 b} \frac{X_{F_{h}}^{*}}{\delta}-I\right]\left(\frac{X}{X_{F_{h}}^{*}}\right)^{\beta_{1}} & \text { if } X<X_{F_{h}}^{*} \\
\frac{\left(a-2 c_{h}+c_{l}\right)^{2}}{9 b} \frac{X}{\delta}-I & \text { if } X \geq X_{F_{h}}^{*}
\end{array}
$$

Where $\beta_{1}$ is the positive ( $>1$ ) root of the quadratic equation $0.5 \sigma^{2} \beta^{2}$ $+\left(r-\delta-0.5 \sigma^{2}\right) \beta-r=0$. The format of the follower value equation when the exchange rate is below the threshold has natural interpretation. The first term, between brackets, is the NPV from the option exercise at $X_{F h}^{*}$. The multiplicative second term is the expected value of the stochastic discounted factor (recall eq.9), from a random time of the follower exercise $T_{F h}^{*}$. The second line in the equation 30 is also the value of simultaneous exercise for any $X$ (for $X<X_{F h}^{*}$, it is the value of a mistake).

The threshold for the high-cost firm as follower is:

$$
X_{F_{h}}^{*}=\frac{\beta_{1}}{\beta_{1}-1} \frac{9 b \delta I}{\left(a-2 c_{h}+c_{l}\right)^{2}}
$$

The leader value for the low-cost firm $L_{l}$ (again, for the less probable high-cost firm as leader, just switch " $l$ " and " $h$ "), if $X<X_{F h}^{*}$, is given by the equation below.

$$
L_{l}=\frac{\left(a-c_{l}\right)^{2}}{4 b} \frac{X}{\delta}+\left[\frac{\left(a-2 c_{l}+c_{h}\right)^{2}}{9 b}-\frac{\left(a-c_{l}\right)^{2}}{4 b}\right] \frac{X_{F_{h}}^{*}}{\delta}\left(\frac{X}{X_{F_{h}}^{*}}\right)^{\beta_{1}}-I(32)
$$

The format of this equation also permits an intuitive explanation. The first term of the right side is the monopoly profit in perpetuity of the

18. For the intermediate steps and additional discussions, see: http://www.puc-rio.br/marco.ind/duopoly3.html 


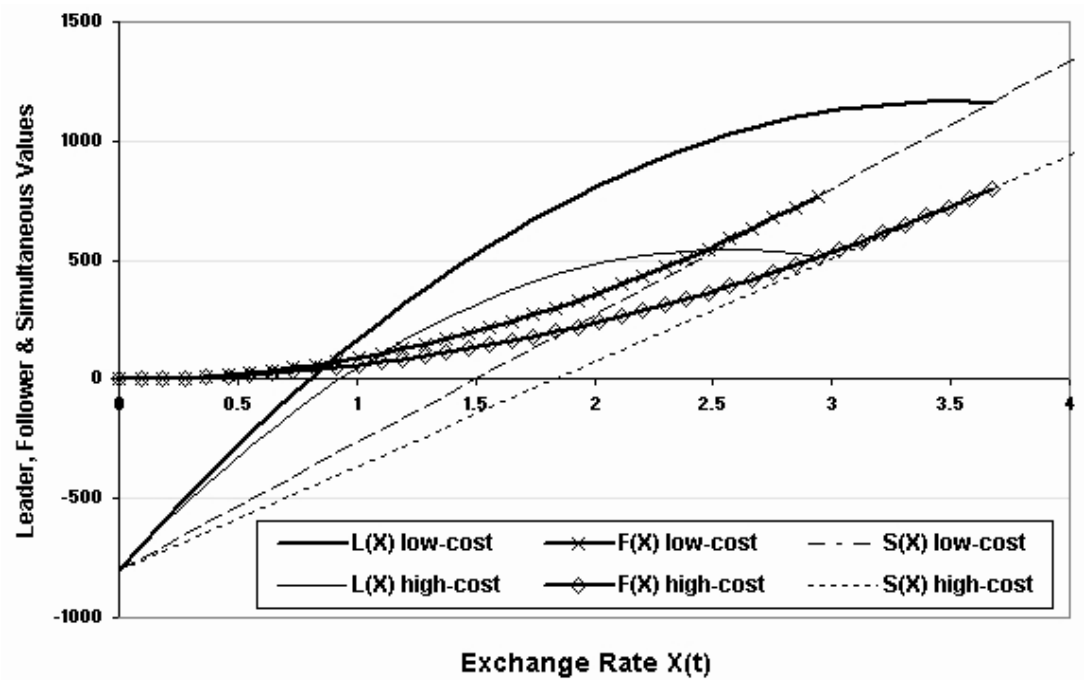

FIGURE 6.- Leader, Follower, and Simultaneous Values for Low-Cost and High-Cost Firms

leader firm. The middle term is the expected present value of the competitive losses (the value between brackets is negative), which will occur at the follower entry (decreasing the monopoly profit in perpetuity). The last term is the investment required to become leader. If $X \geq X_{F h}^{*}$, the leader value is equal to the value of simultaneous investment.

In order to get the leader value, the paper found the same constant $A_{i}$ used in Joaquin and Buttler (eq.16.6e) but in a more heuristic format that permits a quick extension to other demand curves, showed below:

$$
A_{l}=\left[\frac{\left(a-2 c_{l}+c_{h}\right)^{2}}{9 b}-\frac{\left(a-c_{l}\right)^{2}}{4 b}\right] \frac{\left(X_{F_{h}}^{*}\right)^{1-\beta_{1}}}{\delta}
$$

We can identify between brackets the difference of profit flows format: the profit flow from duopoly less the profit flow from monopoly. In this way it is easy to see that this constant is negative: the profit flow from the duopoly phase is lower than the profit flow from the monopolistic phase. The negative value of the constant means that the leader value function is concave, i.e., the effect of the follower entering is to decrease the leader value, as expected by the intuition. 


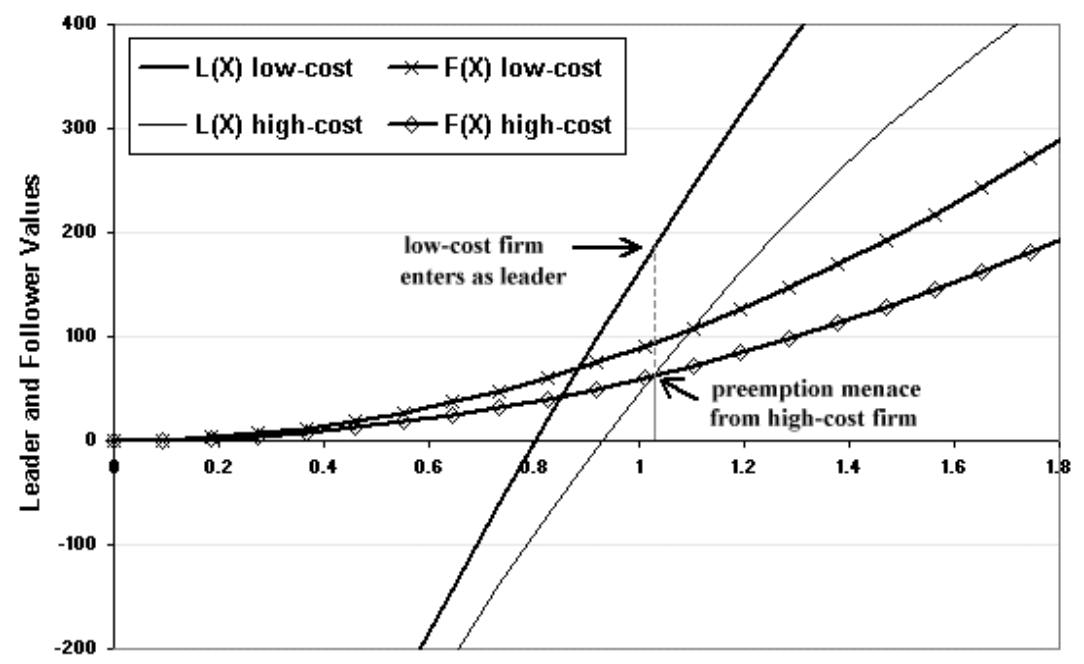

Exchange Rate $X(t)$

FIGURE 7.- The Leader Threshold Determined by the Preemption Menace

Figure 6 shows the leader, follower, and simultaneous investment values for both low-cost and high-cost firms, with the same numerical inputs from the example used by Joaquin and Buttler.

How to estimate the leader threshold? This issue needs some additional considerations when compared with the symmetric case of section III. Without the preemption menace, the low-cost firm will invest optimally at the monopoly threshold $X_{M l}$. However, due to the preemption menace, firms cannot wait so far to invest. If one firm wait until $X=X_{M}$, in some cases the other firm can invest at $X_{M}-\varepsilon$, etc. This process stops when one firm has no more incentive to preempt the rival. Figure 7 shows this issue. It is a zoom from previous figure 6 showing only leader and follower values. Firm $l$ has incentive to become leader if $L_{l} \geq F_{l}$ (point A in figure 7) but it is not necessary to invest at this point because the low-cost firm knows that firm high-cost has incentive to become leader only if $L_{h} \geq F_{h}$. So, low-cost firm strategy to become leader is to invest at $X_{L h}$, when $L_{h}=F_{h}$ and $X_{L h}<X_{F h}$ or, more precisely, at an infinitesimal value before, at $X_{L l}=X_{L h}-\varepsilon$, where $\varepsilon>0$ is an infinitesimal value. This case assumes that $X_{L h}$ exists.

In this case $X_{L l}$ is determined by the high cost firm preemption menace. In other cases, depending mainly on the difference between the operational costs $c_{l}$ and $c_{h}$, the competitive advantage could be higher disappearing the menace of preemption before the optimal monopolistic 


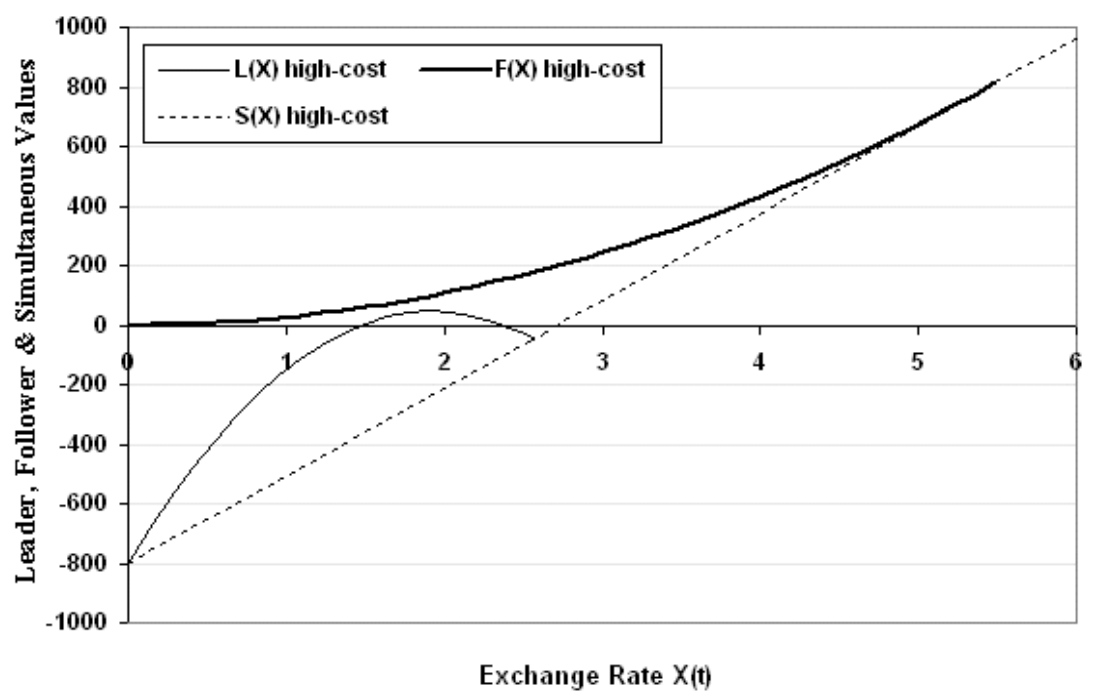

FIGURE 8.- There Is No Danger of Preemption by High-Cost Firm $\mathrm{F}_{\mathrm{h}}>\mathrm{L}_{\mathrm{h}} \forall \mathrm{X}$

exercise at $X=X_{M l}$. In this case the competitive advantage is so high that the low-cost firm ignores the competition by investing at the monopolistic threshold $X_{M l}$ - this is an open-loop strategy. As example, by rising $c_{h}$ (from $\$ 21$ used in Joaquin and Buttler to $\$ 23.5$ ) the values of leader and follower for high-cost firm shows that this firm will never want to be the leader. See figure 8 .

In the figure 8 the follower curve is always above the leader value for the high-cost firm. In this case is always better for the high-cost firm to be the follower, waiting until the exchange rate reach the level $X_{F h}=$ 5.44 in this example. For the rival low-cost firm, this means that there is no preemption menace so that the low-cost firm can ignore the competition by investing at the monopolistic threshold $X_{M l}$. Hence the leader threshold is the minimum between its monopolistic threshold and the other firm minimum level with incentive to become a leader. This is roughly the "result 3" from the Joaquin and Buttler's paper. So, $X_{L l}=$ $\operatorname{Min}\left[X_{M l}, X_{L h}-\varepsilon\right]$.

Is there incentive for collusion? For "new market model" like this case, collusion is never Nash-equilibrium (Huisman and Kort, 1999). With asymmetric firms (competitive advantage), this conclusion is strengthened.

Now, imagine that the initial state of the exchange rate is so favorable that both firms have incentive to become leader because exists 


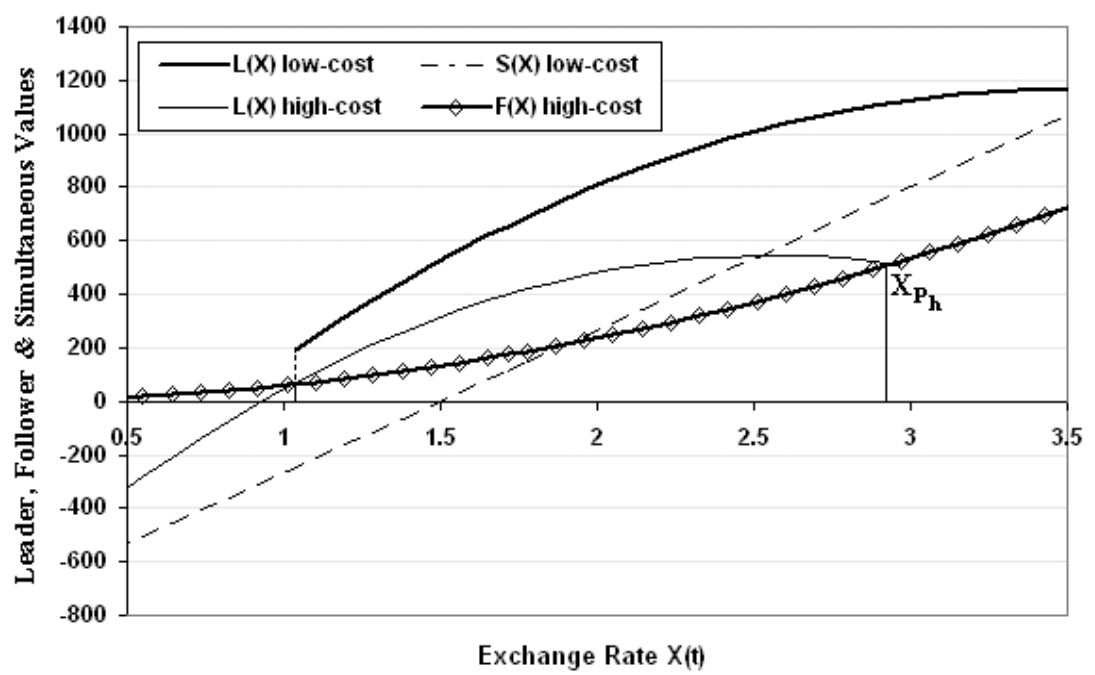

FIGURE 9.- Preemption Region for the High-Cost Firm: From 1.03 to $\sim 2.94$

an exchange rate region where $L>F$ for both firms. However, both firms will be worse in case of simultaneous exercise of the option to invest because the value of simultaneous investment is even lower than the follower value, namely $S<F$ for both firms. It is obvious that, without communication between the firms, there is a positive probability of "mistake" - simultaneous investment getting a value lower than the follower's one. Figure 9 shows this region.

Note that if the high-cost firm has incentives to become leader - the case showed in the figure, the same happen with the low-cost firm. However, we know that the vice-versa is not necessarily valid. Let us denote the region showed in figure 9 as preemption region for the high-cost firm. The existence of this region depends on the parameters, specially the difference between the costs, that is, the competitive advantage value. In the base case of Joaquin and Buttler this region exists. This means that the low-cost firm in this region suffers the risk of obtaining the simultaneous exercise value (see the chart) instead the "logical" or "natural" leader value when investing.

This risk must be considered when analyzing this game. The high-cost firm threat is credible, because if the high-cost firm enters first, the best for the low-cost firm is to resign with the follower role, unless $X \geq X_{F h}$. In reality, high-cost firm as leader and the low-cost firm as follower is also a Perfect Nash equilibrium, even being a less 
intuitive strategic outcome. It is necessary to analyze the mixed strategy probabilities in order to evaluate the probability (or risk) of "mistake" and the probability of the less intuitive high-cost firm emerging as the leader.

Define $X_{P h}$ as the preemption upper bound from the preemption region for the high-cost firm, showed in figure 9 as approximately equal to 2.94. This is the second intersection of $L_{h}$ and $F_{h}$ curves. For values of $X=_{x p h}-\varepsilon$, there is still a small incentive $L_{h}-F_{h}>0$ for the high-cost firm to become leader. This incentive ends when $X$ reaches $X_{P h}$. This upper bound will be used soon in the mixed strategy proposition. The lower bound of the region showed in figure 9 - about 1.03, is the leader threshold (equal for both firms). As in Huisman and Kort model, the strategically optimal option exercise probability is proportional to the difference between the rival $L$ and $F$ values and decreases if the difference between the rival $F$ and $S$ increases. As is known in game theoretic literature, mixed strategies for asymmetric games can look counterintuitive at the first sight. The point is that the mixed strategies probabilities are optimal probabilities (in the sense of maximizing the player payoff), not player strengths or abilities or preferences. In this sense, high-cost firm can be more aggressive to exercise the option than low-cost firms.

In order to determine the mixed strategies probabilities, the paper uses partially the Theorem 8.1 from the Huisman's textbook (2001, p.204). He analyzes the asymmetric duopoly case (chapter 8), but it is a little bit different from our case because the asymmetry there occurs with different investments, whereas here the investments are the same and the asymmetry results from the operational costs.

\section{A. Proposition 2: Mixed Strategy in Asymmetric Duopoly.}

(a) Consider the parameters scenario so that there is a non-empty preemption region for the high-cost firm defined by the region $\left[X_{L h}\right.$, $\left.X_{P h}\right]$. In this region the probabilities of exercise $p_{l}(X)$ and $p_{h}(X)$ for the low-cost and high-cost firms are, respectively: ${ }^{19}$

$$
P_{l}=\frac{L_{h}-F_{h}}{L_{h}-S_{h}} \mid P_{h}=\frac{L_{l}-F_{l}}{L_{l}-S_{l}}
$$

19. Readers of the last section on symmetrical duopoly model will recognize this format and know how to find out results like that using the concept of "atoms" and the maximization process $\left(\partial V_{l} / \partial p_{l}=0\right.$ and $\left(\partial V_{h} / \partial p_{h}=0\right)$. But note that the probabilities $p_{l}$ and $p_{h}$ are functions of the opponent payoffs not the player's payoffs itself. 
Now consider the following possible cases of initial value for the stochastic exchange rate $X(t=0)$ :

(a.1) If the current exchange rate $X(0)$ belongs to the preemption region for the high-cost firm, $\left[X_{L h}, X_{P h}\right]$, then with probability

$$
\operatorname{pr}(\text { low-cost })=\frac{P_{l}\left(1-P_{h}\right)}{P_{l}+P_{h}-P_{l} P_{h}}
$$

low-cost firm invests immediately and high-cost firm invests when $X$ reaches $X_{F h}$. With probability

$$
\operatorname{pr}(\text { high-cost })=\frac{P_{h}\left(1-P_{l}\right)}{P_{l}+P_{h}-P_{l} P_{h}}
$$

high-cost firm invests immediately and low-cost firm invests when $X$ reach $X_{F l}$. And, with probability

$$
\operatorname{pr}(\text { both firms })=\frac{P_{l} P_{h}}{P_{l}+P_{h}-P_{l} P_{h}}
$$

both high-cost firm and low-cost firm invest immediately, the called probability of mistake.

(a.2) If the current exchange rate $X(0)$ is lower than $X_{L h}$ (that is, at the left of the preemption region for the high-cost firm) and lower than $X_{M l}$, then with probability one low-cost firm invests when $X(t)$ reach the value $X_{L l}=\operatorname{minimum}\left(X_{L h}-\varepsilon, X_{M l}\right)$ and high-cost firm invests when $X(t)$ reach $X_{F h}$.

(a.3) If the current exchange rate $X(0)$ is lower than $X_{L h}$ and higher than $X_{M l}$, then with probability one low-cost firm invests immediately and high-cost firm invests when $X(t)$ reach $X_{F h}$.

(a.4) If the current exchange rate $X(0)$ is higher than $X_{P h}$ (that is, at the right of the preemption region for the high-cost firm) and lower than $X_{F h}$, then with probability one low-cost firm invests immediately and high-cost firm invests when $X$ reach $X_{F h}$.

(a.5) If the current exchange rate $X(0)$ is higher or equal than $X_{F h}$ that is, a region where is optimal for both firms to invest, then with probability one both firms invest immediately.

(b) If the preemption region for the high-cost firm is an empty set (there is no $X$ that $L \geq F$ for high-cost firm), then:

Low-cost firm will invest with probability one at $X_{M l}$ as leader and high-cost firm will invest with probability one only at $X_{F h}$, as follower. 


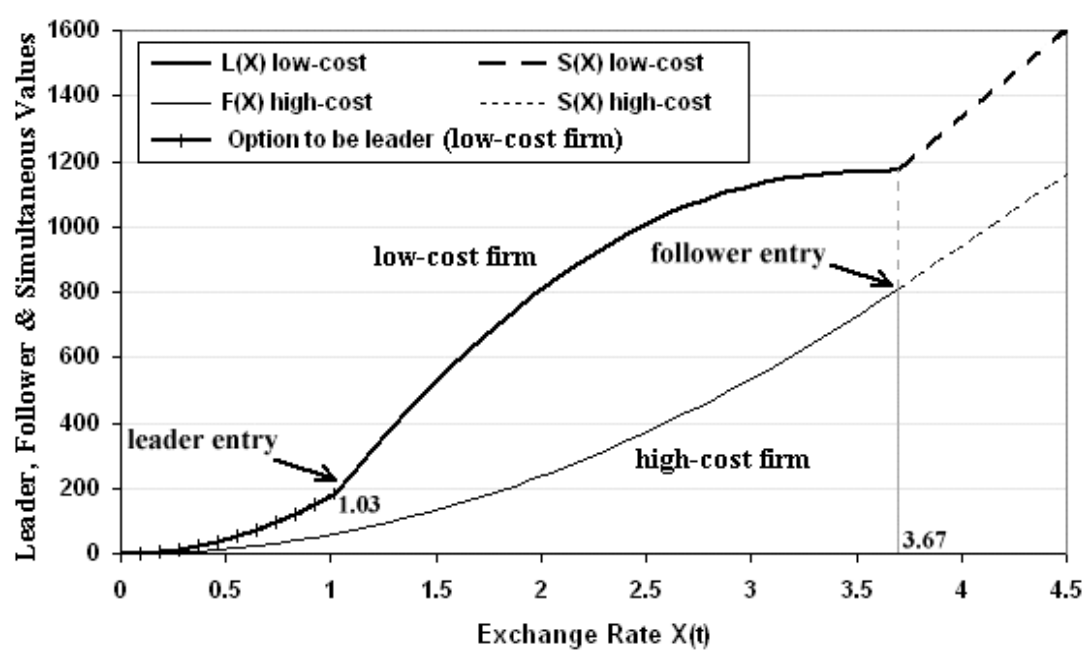

FIGURE 10.- The Main Perfect Nash Equilibrium in Asymmetric Duopoly

Proof: By using the concept of "atoms" we can follow the same steps presented at section III for the simultaneous game at $\tau$ (when one or two firms invest with probability 1), proving (a.1) with a maximization process to get the equations $34,35,36$ and 37 , so that there are no unilateral incentives to deviate. Items (a.2), (a.3) and (a.4) follow because the low-cost firm is better off exercising the option than waiting if $X(t)>X_{L l}$, and it has no incentive to deviate from the option exercise strategy when $X(t)=X_{L l}$, whereas for the high-cost firm "wait and see" is better than the option exercise for $X(t)<X_{F h}$. Item (a.5) follows because the option exercise - even simultaneously, is better than wait and see for both firms. Finally, item (b) results from the fact that in this case never is optimal for high-cost to enter as leader, so that there is no menace of preemption and low-cost firm maximizes its profit by entering only at the monopolistic threshold value $X_{M l}$.

Figure 10 shows the more intuitive or main Perfect Nash equilibrium with low-cost firm entering as leader and high-cost firm as follower.

In the figure 10 appears a new value function: the option to become leader. This value function is calculated with the leader threshold $X_{L l}$, by using the expected value of stochastic discount factor from the random time to $X(t)$ reaches $X_{L}$, times the leader value function for the low-cost firm. 


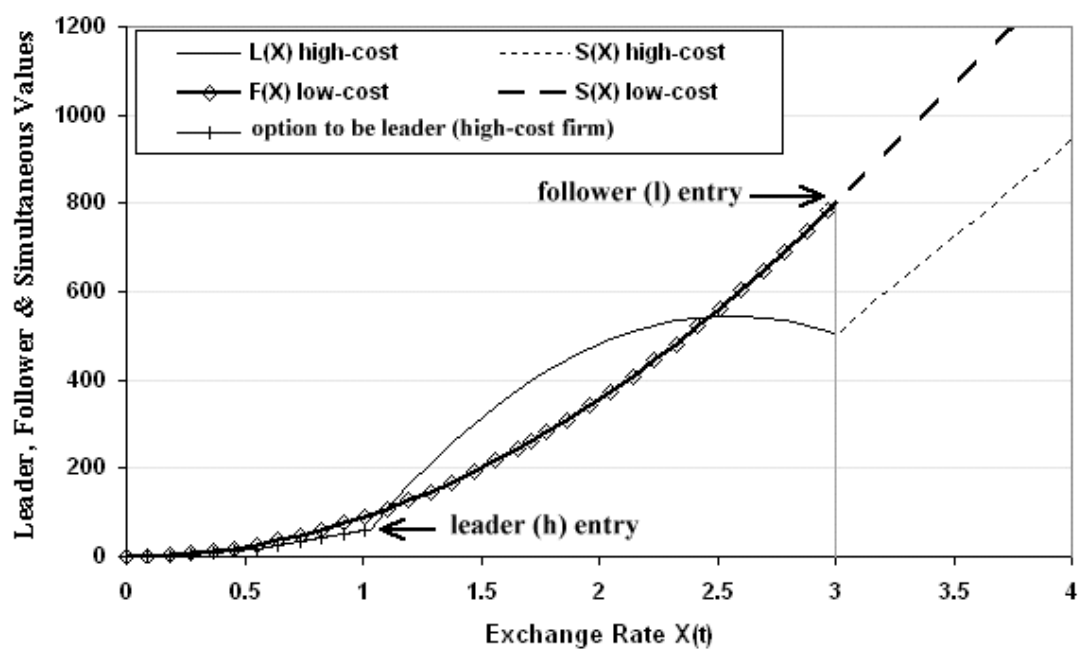

FIGURE 11.- The Secondary Perfect-Nash Equilibrium in Pure Strategies

Figure 11 shows the less intuitive or secondary Perfect Nash equilibrium, with the high-cost firm being the leader and the low-cost firm being the follower.

Recall that if the game starts with the exchange rate $X<X_{L}$, the occurrence probability for this equilibrium is zero. However this probability can be strictly positive if $X$ starts at the called preemption region for the high-cost firm.

Recall also that, depending on the parameters, there exists the possibility of mistake - simultaneous investment when the optimal for both firms is only one firm active in the market. If this mistake happens (has positive probability if the initial exchange rate is in the preemption region for the high-cost firm), deviation is not feasible because the investment is irreversible.

\section{Conclusion}

In this paper was presented a short bibliographical development of option games and the basic related concepts. The paper discussed negative externality models of symmetric and asymmetric duopoly under uncertainty, being the former of great conceptual relevance and the latter of great practical appeal. Concepts like preemption, 
non-binding collusion, and mixed strategies were discussed for both symmetric and asymmetric cases. The reader saw that in many situations exists a strictly positive probability of "mistake" - simultaneous option exercise when the best for both firms is only one firm investing. Contrary to popular belief, this positive probability of mistake can occur even for asymmetric duopoly under uncertainty.

The major contribution of this paper is to formalize two equivalent ways to calculate the key elements to set the stopping time equilibrium strategies, i.e., the values and thresholds for the leader and the follower, in real options games where the players play simple threshold strategies. In certain problems one approach can be preferable than the other creating an option to solve the option games.

Accepted by: Prof. L. Trigeorgis, Guest Editor, April 2007

Prof. P. Theodossiou, Editor-in-Chief, April 2007

\section{References}

Basar, T., and Olsder, G. J. 1995. Dynamic Non-Cooperative Game Theory. San Diego: Academic Press Inc., $2^{\text {nd }}$ ed.

Bhattacharya, S. 1979. Imperfect information, dividend policy, and 'the bird in the hand fallacy'. Bell Journal of Economics 10: 259-270.

Birge, J.R., and Louveaux, F. 1997. Introduction to Stochastic Programming. New York: Springer Verlag.

Black, F., and Scholes, M. 1973. The pricing of options and corporate liabilities. Journal of Political Economy 81: 637-659.

Brennan, M.J., and Schwartz, E.S. 1985. Evaluating natural resource investment. Journal of Business, 58(2): 135-157.

Décamps, J.-P, and Mariotti, T. 2004. Investment timing and learning externalities. Journal of Economic Theory 118: 80-102

Dias, M.A.G. 1997. The timing of investment in E\&P: Uncertainty, irreversibility, learning, and strategic consideration. SPE paper 37949. Dallas: Proceedings of 1997 SPE Hydrocarbon Economics and Evaluation Symposium, 135-148.

Dias, M.A.G.; Rocha, K.M.C.; and Teixeira, J.P. 2004. The optimal investment scale and timing: A real option approach to oilfield development. Montreal: $8^{\text {th }}$ Annual International Conference on Real Options, June 2004. Available at http://www.realoptions.org/.

Dixit, A.K., and Pindyck, R.S. 1994. Investment under Uncertainty. Princeton: Princeton University Press.

Dixit, A.K.; Pindyck, R. S.; and Sødal, S. 1999. A markup interpretation of optimal investment rules. Economic Journal 109: 179-189. 
Dockner, E.; Jorgensen, S.; Van Long, N.; and Sorger, G. 2000. Differential Games in Economics and Management Science. Cambridge: Cambridge University Press.

Dutta, P.K., and Rustichini, A. 1995. (s, S) equilibria in stochastic games. Journal of Economic Theory 67: 1-39

Fudenberg, D., and Tirole, J. 1985. Pre-emption and rent equalization in the adoption of new technology. Review of Economic Studies 52: 383-401.

Fudenberg, D. and Tirole, J. 1991. Game Theory. Cambridge and London: MIT Press.

Grenadier, S.R. 2002. Option exercise games: an application to the equilibrium investment strategies of firms. Review of Financial Studies 15: 691-721.

Grenadier, S.R. (eds.) 2000. Game Choices - the Intersection of Real Options and Game Theory. London: Risk Books.

Huisman, K.J.M. 2001. Technology Investment: A Game Theoretic Real Options Approach. Boston: Kluwer Academic Publishers.

Huisman, K. J. M., and Kort, P. M. 1999. Effects of strategic interactions on the option value of waiting. Working paper. Tilburg: Tilburg University.

Joaquin, D.C., and Butler, K.C. 2000. Competitive investment decisions: a synthesis. In M.J. Brennan and L. Trigeorgis (eds.). Project Flexibility, Agency, and Competition - New Developments in the Theory and Applications of Real Options. Oxford: Oxford University Press: 324-339.

Kester, W.C. 1984. Today's options for tomorrow's growth. Harvard Business Review 62: 153-160.

Lambrecht, B. 2001. The impact of debt financing on entry and exit in a duopoly. Review of Financial Studies 14(3): 765-780

Lambrecht, B., and Perraudin, W. 1994. Option games. Working paper. Cambridge: Cambridge University and CEPR.

Leland, H.E., and Pyle, D.H. 1977. Informational asymmetries, financial structure, and financial intermediation. Journal of Finance 32: 371-387.

McDonald, R., and Siegel, D. 1986. The value of waiting to invest. Quarterly Journal of Economics 101: 707-727.

Merton, R.C. 1973. Theory of rational option pricing. Bell Journal of Economics and Management Science 4: 141-183.

Myers, S.C. 1977. Determinants of corporate borrowing. Journal of Financial Economics 5: 147-175.

Myers, S., and Majluf, N. 1984. Corporate financing and investment decisions when firms have information that investors do not have. Journal of Financial Economics 13: 187-221.

Paddock, J.L.; Siegel, D.R.; and Smith, J.L. 1988. Option valuation of claims on real assets: the case of offshore petroleum leases. Quarterly Journal of Economics 103: 479-508.

Ross, S.A. 1977. The determination of financial structure: the incentive signaling approach. Bell Journal of Economics 8: 23-40.

Smets, F.R. 1993. Essays on Foreign Direct Investment. New Haven: Yale University, Doctoral dissertation. 
Smit, H.T.J., and Ankum, L.A. 1993. A real options and game-theoretic approach to corporate investment strategy under competition. Financial Management 22: 241-250.

Smit, H.T.J., and Trigeorgis, L. 1993. Flexibility and commitment in strategic investment. Working paper. Rotterdam: Tinbergen Institute, Erasmus University at Rotterdam.

Smit, H.T.J., and Trigeorgis, L. 2004. Strategic Investment - Real Options and Games. Princeton: Princeton University Press.

Tourinho, O.A.F. 1979. The Valuation of Reserves of Natural Resources: an Option Pricing Approach. Berkeley: Doctoral dissertation, University of California, Berkeley.

Trigeorgis, L. 1996. Real Options - Managerial Flexibility and Strategy in Resource Allocation. Cambridge, MA: MIT Press.

Trigeorgis, L.G. 1986. Valuing Real Investment Opportunities: An Options Approach to Strategic Capital Budgeting. Cambridge, MA: Harvard University, Doctoral dissertation.

Trigeorgis, L. 1991. Anticipated competitive entry and early preemptive investment in deferrable projects. Journal of Economics and Business 43: 143-156.

Trigeorgis, L., and Mason, S.P. 1987. Valuing managerial flexibility. Midland Corporate Finance Journal (Spring): 14-21.

Ziegler, A. 1999. A Game Theory Analysis of Options - Contributions to The Theory of Financial Intermediation in Continuous Time. Berlin: Springer-Verlag Berlin Heidelberg. 